\title{
Differences in Kinematic Characteristics Between 2-point and 3-point Basketball Shooting Motions - A Case Study
}

\author{
Dimitrije Cabarkapa ${ }^{1 *}$, Andrew C. Fry ${ }^{1}$, Michael A. Deane ${ }^{1}$ \\ ${ }^{1}$ Jayhawk Athletic Performance Laboratory, University of Kansas, Lawrence, KS, USA
}

DOI: $10.36348 /$ jaspe.2021.v04i03.001

| Received: 23.02.2021 | Accepted: 05.03.2021 | Published: 08.03.2021

*Corresponding author: Dimitrije Cabarkapa

Abstract

Basketball has become one of the most popular international sports in which a successful game outcome is highly contingent upon optimal shooting performance. The purpose of this case study was to quantify and examine the kinematic changes in shooting motion as a player progresses from mid-range 2-point shots to beyond the 3-point line. One former collegiate basketball player performed 50 mid-range 2-point $(5.20 \mathrm{~m})$ and 50 3-point $(6.75 \mathrm{~m})$ shots divided into 10 sets separated by 1-2-minute rest intervals. Two high-definition cameras recording at 30 fps positioned perpendicular to the subject's sagittal plane of motion were used for data collection. The first camera positioned $10 \mathrm{~m}$ away was used to capture body kinematics, while the second camera positioned $15 \mathrm{~m}$ away was used to capture the trajectory data. The kinematic variables captured at the initial phase of the shooting motion (Phase1) were knee angle, hip angle, ankle angle, elbow height, shoulder angle, elbow angle, and basketball height and at the time point of ball release (Phase 2) were shoulder angle at release, heel height, basketball release height, trajectory height, and ball entry angle. The findings of this case study indicate that greater flexion in the knee joint during the Phase 1 and greater heel height indicating larger vertical displacement during the Phase 2 of the shooting motion were the main kinematic adjustments influenced by the increased shooting distance. Therefore, we may assume that these changes were made to achieve greater ground reaction forces to compensate for the increased distance from the rim.

Keywords: Sport, coaching, basketball, sport performance, shooting technique, biomechanics.

Copyright () 2021 The Author(s): This is an open-access article distributed under the terms of the Creative Commons Attribution 4.0 International License (CC BY-NC 4.0) which permits unrestricted use, distribution, and reproduction in any medium for non-commercial use provided the original author and source are credited.

\section{INTRODUCTION}

Basketball has become one of the most popular international sports in which successful game outcome is highly contingent upon optimal shooting performance. Previous research has found that shooting accuracy factors favorably to scoring greater number of the overall points and points per quarter $[1,2]$. Winning teams had significantly greater number of successfully made free throw, 2-point, and 3-point shots when compared to losing teams $[1,2]$. Besides superior offensive efficiency, the 2-point shooting percentage was one of the critical variables capable of discriminating between the winning and losing team in both balanced (10-22 point difference) and unbalanced (22-34 point difference) basketball games [1]. Moreover, Trninic et al. discovered that the ability to control the offensive strategy and hold the ball until an open shooting opportunity develops resulted in an improved shooting percentage [3]. Therefore, it is understandable why many players on various levels of basketball competition are constantly looking for techniques that can help them improve their shooting performance and help increase the team's winning probabilities.

In the lay literature there are as many different coaching cues for the enhancement of shooting performance as there are coaches. Those cues include but are not limited to greater knee bend, proper followthrough, optimal elbow flexion, greater shooting arc, etc. [4-6]. Although they may be greatly effective, there is a lack of scientific literature addressing kinetic and kinematic characteristics of the most commonly used shooting motions as well as how they change with increased shooting distance. A couple of recently conducted studies focused on examining ground reaction forces for sport specific motions such as basketball dunking and volleyball blocking approaches $[7,8]$. Hence, the purpose of this case study was to quantify and examine the kinematic changes in shooting motion as a player progresses from mid-range 2-point shots to beyond the 3-point line. 
Dimitrije Cabarkapa et al., J Adv Sport Phys Edu, Mar, 2021; 4(3): 19-23

\section{METHODS}

One former collegiate basketball player (age $=27$; height $=208 \mathrm{~cm}$; body mass $=115.2 \mathrm{~kg}$ ) performed 50 mid-range 2-point $(5.20 \mathrm{~m})$ and 503 point $(6.75 \mathrm{~m})$ shots divided into 10 sets separated by 1 2 -minute rest intervals. Two high-definition cameras (Canon PowerShot SX530) recording at $30 \mathrm{fps}$ positioned perpendicular to the subject's sagittal plane of motion were used for data collection. The first camera positioned $10 \mathrm{~m}$ away was used to capture body kinematics, while the second camera positioned $15 \mathrm{~m}$ away was used to capture the trajectory data. Kinematic variables were derived from the video recordings by utilizing video analysis software (Kinovea, Version 0.9.3). All testing procedures performed in this study were previously approved by the University's Institutional Review Board.

Dependent variables analyzed during the initial concentric phase of the shooting motion (Phase 1) were: knee angle (internal angle between thigh and shank), ankle angle (internal angle between shank and an imaginary horizontal line parallel to the ground), hip angle (internal angle between torso and thigh), shoulder angle (internal angle between the upper arm and torso), elbow angle (internal angle between upper arm and forearm), basketball height (perpendicular distance from the center of the ball to the ground), and elbow height (perpendicular distance between the olecranon process and the ground). Dependent variables analyzed at the time point of the ball release (Phase 2) were: shoulder angle at release (angle between fully extended upper limb and an imaginary horizontal line parallel to the ground), basketball release height (perpendicular distance from the center of the ball to the ground), heel height (perpendicular distance from the heel to the ground), entry angle (internal angle between the ball entry trajectory and an imaginary horizontal line parallel to the ground), and trajectory height (perpendicular distance from the greatest basketball trajectory height to the ground). The graphical representation of the kinematic variables is presented in Figure-1.

One-way Analysis of Variance (ANOVA) was used to determine differences in kinematic parameters between 2-point and 3-point shots. Cohen's D effect sizes were calculated to compare the difference between the means. Pearson product-moment correlations were used to examine the correlation pattern between the dependent variables. Statistical significance was set a priori to $\mathrm{p}<0.05$. Statistical software SPSS 25.0 (SPSS Inc., Chicago, IL, USA) was used for data analysis.

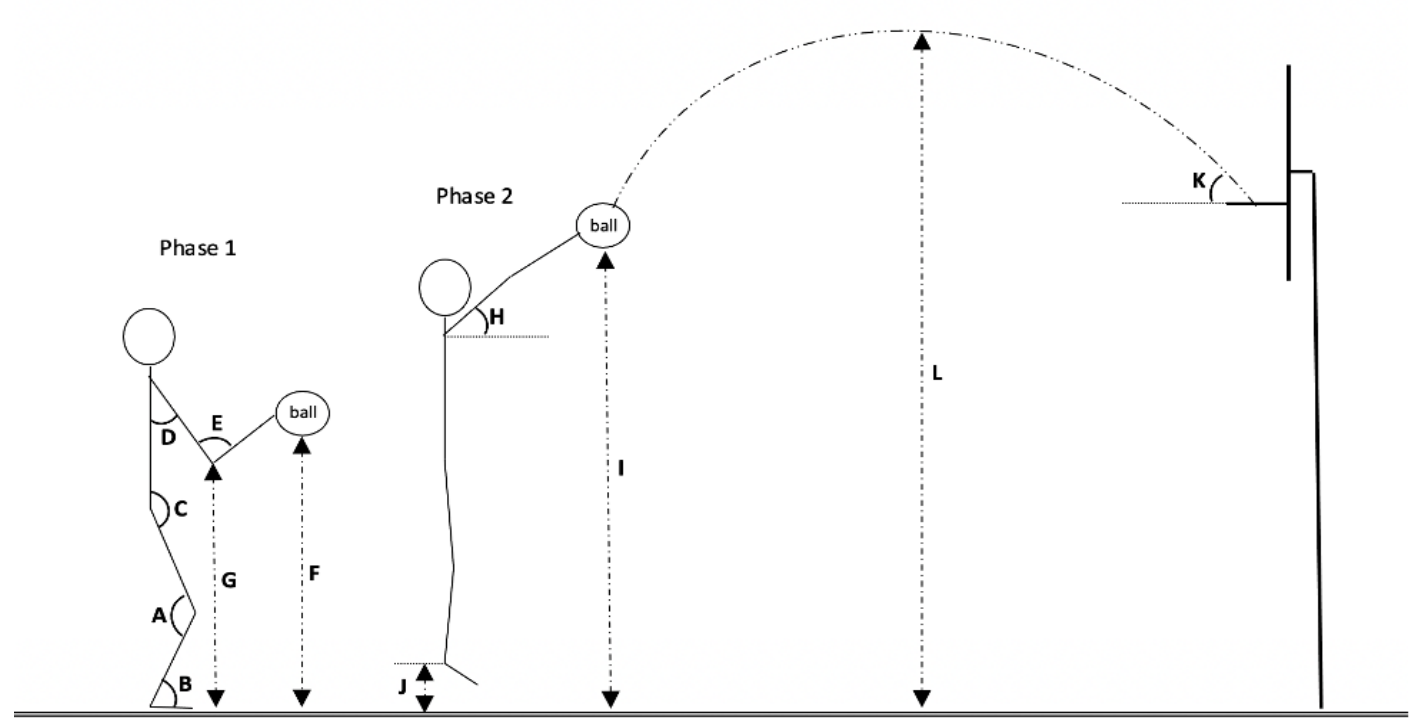

Figure-1: Graphical representation of the dependent variables examined in this study. Knee angle (A); ankle angle (B); hip angle (C); shoulder angle (D); elbow angle (E); basketball height (F); elbow height (G); shoulder angle at release (H); basketball release height $(\mathrm{I})$; heel height $(\mathrm{J})$; entry angle $(\mathrm{K})$; trajectory height $(\mathrm{L})$. Phase 1 - initial concentric phase of the shooting motion. Phase 2 - shooting phase at the time point of the ball release.

\section{RESULTS}

Mean values and standard deviations ( $\overline{\mathrm{x}} \pm \mathrm{SD})$, $95 \%$ confidence intervals $(95 \% \mathrm{CI}), \mathrm{p}$-values, and the effect sizes are presented in Table-1. Correlation matrix is presented in Table-2. Significant differences between mid-range 2-point and 3-point shooting motions were found to exist for all dependent variables except for ankle, hip, and shoulder angle during the Phase 1 and shoulder angle at release during the Phase 2 of the shooting motion. 
Dimitrije Cabarkapa et al., J Adv Sport Phys Edu, Mar, 2021; 4(3): 19-23

\begin{tabular}{|c|c|c|c|c|c|}
\hline & Dependent variables & 2-point & 3-point & p-value & Effect size \\
\hline \multirow[t]{7}{*}{ Phase 1} & Knee angle (deg) & $\begin{array}{l}102.2 \pm 2.3 \\
{[97.8-106.7]}\end{array}$ & $\begin{array}{l}98.6 \pm 3.7 \\
{[91.3-105.9]}\end{array}$ & $<0.001$ & 1.17 \\
\hline & Hip angle (deg) & $\begin{array}{l}137.0 \pm 2.9 \\
{[131.3-142.7]}\end{array}$ & $\begin{array}{l}137.1 \pm 3.3 \\
{[130.6-143.6]}\end{array}$ & 0.898 & 0.03 \\
\hline & Ankle angle (deg) & $\begin{array}{l}70.0 \pm 2.1 \\
{[65.9-74.1]}\end{array}$ & $\begin{array}{l}69.3 \pm 2.4 \\
{[64.6-74.0]}\end{array}$ & 0.140 & 0.31 \\
\hline & Elbow height $(\mathrm{cm})$ & $\begin{array}{l}167.7 \pm 3.8 \\
{[160.3-175.1]}\end{array}$ & $\begin{array}{l}164.2 \pm 4.2 \\
{[155.9-172.4]}\end{array}$ & $<0.001$ & 0.87 \\
\hline & Shoulder angle (deg) & $\begin{array}{l}100.6 \pm 3.4 \\
{[93.9-107.3]}\end{array}$ & $\begin{array}{l}99.1 \pm 2.3 \\
{[94.6-103.6]}\end{array}$ & 0.014 & 0.52 \\
\hline & Elbow angle (deg) & $\begin{array}{l}47.1 \pm 2.7 \\
{[41.8-52.4]}\end{array}$ & $\begin{array}{l}45.1 \pm 2.5 \\
{[40.2-50.0]}\end{array}$ & $<0.001$ & 0.77 \\
\hline & Basketball height $(\mathrm{cm})$ & $\begin{array}{l}203.7 \pm 2.4 \\
{[198.9-208.4]}\end{array}$ & $\begin{array}{l}198.9 \pm 3.0 \\
{[193.0-204.8]}\end{array}$ & $<0.001$ & 1.77 \\
\hline \multirow[t]{5}{*}{ Phase 2} & Shoulder angle at release (deg) & $\begin{array}{l}57.9 \pm 1.7 \\
{[54.6-61.2]}\end{array}$ & $\begin{array}{l}57.4 \pm 1.5 \\
{[54.5-60.3]}\end{array}$ & 0.195 & 0.31 \\
\hline & Heel height $(\mathrm{cm})$ & $\begin{array}{l}19.6 \pm 1.0 \\
{[17.6-21.6]}\end{array}$ & $\begin{array}{l}24.2 \pm 1.1 \\
{[22.0-26.4]}\end{array}$ & $<0.001$ & 4.38 \\
\hline & Basketball release height $(\mathrm{cm})$ & $\begin{array}{l}256.6 \pm 4.7 \\
{[247.4-256.8]}\end{array}$ & $\begin{array}{l}263.5 \pm 4.9 \\
{[253.9-273.1]}\end{array}$ & $<0.001$ & 1.44 \\
\hline & Trajectory height $(\mathrm{cm})$ & $\begin{array}{l}406.5 \pm 6.4 \\
{[393.9-419.0]}\end{array}$ & $\begin{array}{l}439.1 \pm 6.0 \\
{[427.3-450.9]}\end{array}$ & $<0.001$ & 5.26 \\
\hline & Entry angle (deg) & $\begin{array}{l}37.9 \pm 2.7 \\
{[32.6-43.2]}\end{array}$ & $\begin{array}{l}40.1 \pm 2.0 \\
{[36.2-44.0]}\end{array}$ & $<0.001$ & 0.93 \\
\hline
\end{tabular}

Table-2: Correlation Matrix. Knee Angle (KA); Hip Angle (HA); Ankle Angle (AA); Elbow Height (EH); Shoulder Angle (SA); Elbow Angle (ELA); Basketball Height (BH); Shoulder Angle at Release (SAR); Heel Height (HH); Basketball Release Height (BRH); Trajectory Height (TH); Ball Entry Angle (BEA). Shaded values represent statistically significant correlation $(\mathrm{p}<0.05)$.

\begin{tabular}{|l|l|l|l|l|l|l|l|l|l|l|l|}
\hline & KA & HA & AA & EH & SA & ELA & BH & SAR & HH & BRH & TH \\
\hline HA & 0.59 & & & & & & & & & & \\
\hline AA & 0.29 & 0.24 & & & & & & & & & \\
\hline EH & 0.82 & 0.58 & 0.29 & & & & & & & & \\
\hline SA & 0.40 & 0.14 & 0.17 & 0.60 & & & & & & & \\
\hline ELA & -0.12 & -0.37 & -0.09 & -0.21 & 0.04 & & & & & & \\
\hline BH & 0.85 & 0.46 & 0.26 & 0.88 & 0.53 & -0.07 & & & & & \\
\hline SAR & -0.07 & -0.02 & -0.07 & 0.01 & 0.11 & 0.14 & 0.04 & & & & \\
\hline HH & -0.50 & -0.07 & -0.16 & -0.42 & -0.23 & -0.24 & -0.64 & -0.11 & & & \\
\hline BRH & -0.32 & -0.01 & -0.05 & -0.24 & -0.15 & -0.28 & -0.43 & -0.22 & 0.53 & & \\
\hline TH & -0.51 & -0.04 & -0.12 & -0.43 & -0.26 & -0.35 & -0.67 & -0.08 & 0.84 & 0.56 & \\
\hline BEA & -0.15 & -0.14 & 0.04 & -0.09 & 0.10 & -0.08 & -0.24 & 0.01 & 0.40 & 0.36 & 0.54 \\
\hline
\end{tabular}

\section{DISCUSSION}

The findings of the present study indicate notable differences in the examined kinematic parameters as the player progresses from the mid-range 2 -point shots to beyond the 3 -point line. The increase in shooting distance during Phase 1 of the shooting motion led to decreased elbow height and basketball height positioning as well as greater flexion in the knee, elbow, and shoulder joints. Despite reaching the level of statistical significance, the effect size of the change in the shoulder angle was much smaller than the one observed in the knee joint. Also, the shoulder angle demonstrated lower correlation magnitudes with the elbow and basketball height when compared to the knee angle variable. Therefore, the observed decrease in the elbow and basketball height during the Phase 1 of the 3 -point shooting motion is primarily attributed to the greater flexion in the knee joint, not as a consequence of greater shoulder flexion resulting in an elbow drop. Although resembling the similar pattern of the smaller knee, hip, and elbow angles observed during 3-point shooting, the differences observed by Elliot \& White within a cohort of highly trained female basketball players were not significantly different as were the ones obtained in the present study [9]. This may be attributed 
Dimitrije Cabarkapa et al., J Adv Sport Phys Edu, Mar, 2021; 4(3): 19-23

in part to the recent changes in the 3-point line regulations by increasing the shooting distance from 6.25 to $6.75 \mathrm{~m}$. Furthermore, the importance of the knee angle for successful basketball shooting performance has been also observed by Ammar et al. who focused on examining the kinematic differences between made and missed free throw shots during the learning process [10]. The increased total motion in the knee joint achieved by less flexion during the preparatory phase, and greater extension at the time point of ball release was critical for determining the successful shooting outcome [10].

During the Phase 2 of the shooting motion, the shoulder angle at release was unchanged and it showed low correlation with the other dependent variables. However, shooting beyond the 3-point line required a greater ball entry angle, as well as greater heel height, trajectory height, and basketball release height. The increase in heel height indicated greater vertical jump displacement, and was positively correlated with an increased in trajectory height and ball release height, which ultimately led to a greater entry angle of the basketball. Some of our findings were contradictory to those of Okazaki \& Rodacki who reported that the increase in shooting distance resulted in smaller shoulder flexion angles and lower ball release height [11]. It has been suggested that the release angle of the ball is highly contingent upon the flexion in the shoulder joint and if unaltered with the increase in shooting distance, it may lead to greater force production requirements [11]. Furthermore, the players with diminished ability to generate force may experience difficulties when performing a jump shooting motion [12]. Thus, the lack of significant changes in the shoulder angle at release as observed in this study may be influenced by the kinematic alterations during the Phase 1 of the shooting motion, allowing for greater ground reaction force production. In addition, it has been found that anthropometric characteristics such as limb length may have a strong influence on the basketball release height [12]. When examining kinematic changes by playing position influenced with an increase in shooting distance, the researchers found that the average release height for centers at $6.40 \mathrm{~m}$ away from the basket was approximately $223 \mathrm{~cm}$ [13]. The lower release heights of the ones observed in the present study may be mainly attributed to the differences in the height of the participants. In conjunction with the differences in release height of the basketball, despite not reaching the level of statistical significance, it has been found that centers which tend to be the tallest players attain a lower entry angle when compared to other playing positions [14]. The average entry angle for shots taken at $6.40 \mathrm{~m}$ away from the basket was 36.6 degrees which is close to the values obtained in this study [14].
Based on the findings of this case study we can conclude that greater flexion in the knee joint during the Phase 1 and greater heel height indicating larger vertical displacement during the Phase 2 of the shooting motion were the main kinematic adjustments influenced by the increase in the shooting distance from a 2-point to a 3-point shot. We assume that these changes were made to achieve greater ground reaction forces, and to compensate for the increased distance from the rim. Further research needs to examine the relationships between kinetic and kinematic variables in order to obtain a better understanding of the biomechanical demands as the player progresses from 2-point to 3point shooting range that can potentially lead to enhancement in shooting performance. Furthermore, understanding the mechanics of successful basketball shooting will also permit a better understanding and role of physiological influences on game and practice performances.

\section{REFERENCES}

1. Csataljay, G., O’Donoghue, P., Hughes, M., \& Dancs, H. (2009). Performance indicators that distinguish between winning and losing teams in basketball. International Journal of Performance of Analysis in Sport, 9(1), 60-66.

2. Csataljay, G., James, N., Hughes, M., \& Dancs, H. (2012). Performance differences between winning losing basketball teams during close, balanced and unbalanced quarters. Journal of Human Sport and Exercise, 7(2), 356-364.

3. Trninic, S., Dizdar, D., \& Luksic, E. (2002). Differences between winning and defeated top quality basketball teams in final tournaments of European club championship. Collegium Antropologicum, 26(2), 521-531.

4. Haefner, J. (n.d). Five of the biggest basketball shooting mistakes (and how to fix them). Retrieved December 31, 2020, from https://www.breakthroughbasketball.com/fundame ntals/shooting/5-shootingmistakes.html?filterreviews=upvotes

5. Miller, M. (2018, November 27). Shooting Form: 4 major components. Retrieved December 31, 2020, from https://www.nrbasketballacademy.com/2018/11/2 7/shooting-form-4-major-components/

6. Passalacqua, A. (November 20, 2018). Three common shooting techniques that are wrong. Retrieved December 31, 2020, from https://shootinschool.com/3-common-shootingtechniques-that-are-wrong/

7. Cabarkapa, D., \& Fry, A. C. (2019) Ground reaction forces during a basketball dunk. Slovak Journal of Sport Science, 6(1), 22-37.

8. Cabarkapa, D., Fry, A. C., Cabarkapa, D. X., Rogers, A. C., \& Mosier, E. M. (2020). Ground reaction forces of commonly sed volleyball 
Dimitrije Cabarkapa et al., J Adv Sport Phys Edu, Mar, 2021; 4(3): 19-23

blocking approaches. Journal of Kinesiology and Exercise Sciences, 89(30), 13-20.

9. Elliott, B. C., \& White, E. (1989). A kinematic and kinetic analysis of the female two point and three point jump shots in basketball. The Australian Journal of Science and Medicine in Sport, 21(2), 7-11.

10. Ammar, A., Chtourou, H., Abdelkarim, O., Parish, A., \& Hoekeimann, A. (2016). Free throw shot in basketball: Kinematic Analysis of scored and missed shots during a learning process. Sport Science and Health, 12(1), 27-33.

11. Okazaki, V. H. A., \& Rodacki, A. L. F. (2012). Increased distance of shooting on basketball jump shot. Journal of Sport Science and Medicine, 11(1), 231-237.

12. Okazaki, V. H. A., Rodacki, A. L. F., \& Satern, M. N. (2015). A review on the basketball jump shot. Sports Biomechanics, 14(2), 190-205.

13. Miller, S., \& Bartlett, R. (1996). The relationship between basketball shooting kinematics, distance and playing position. Journal of Sport Sciences, 14(1), 243-253.

14. Stojanovic, E., Radenkovic, M., Bubanj, S., \& Stankovic, R. (2019). Kinematic parameters of the jump shot in elite male basketball players. Facta Universitatis, Series: Physical Education and Sport, 17(2), 237-245. 